Pacific Journal of Mathematics

DIFFERENTIAL SYSTEMS WITH IMPULSIVE 


\title{
DIFFERENTIAL SYSTEMS WITH IMPULSIVE PERTURBATIONS
}

\author{
S. G. PANDIT
}

Properties of solutions of measure differential equations are investigated with emphasis on the impulses. A variation of parameters formula, expressing solutions of nonlinear measure differential system in terms of the solution of linear measure differential system and the strength of the impulses, is developed and a result on the asymptotic stability is established.

1. Introduction. Measure differential equations have been investigated by Das and Sharma [3], Leela [4,5], Raghavendra and Rao [6] and Schmaedeke [7], among others. These equations provide good models for many a physical and biological system. The fact that their solutions are discontinuous renders the conventional methods of ordinary differential equations unapplicable, and thus their study becomes interesting. In [3-6], the equation

$$
D x=F(t, x)+G(t, x) D u
$$

is studied as an impulsively perturbed system of the ordinary differential equation

$$
x^{\prime}=F(t, x) \quad\left({ }^{\prime}=\frac{d}{d t}\right) .
$$

In [7], it is investigated from the view point of optimal control theory, that is, $G$ is assumed to be independent of $x$. In this paper, we are concerned with the system

$$
D x=f(t, x)+A x D u+g(t, x) D u,
$$

which is treated as a perturbed system of the linear system

$$
D x=A x D u \text {. }
$$

This gives a more clear picture of the effect of impulses on the behavior of solutions. Deviations from the conventional theory, which are obviously expected, are noted in particular.

Theorem 2.1 indicates the possible abrupt behavior of solutions of (1.3) at the points of discontinuity of $u$ (see also Remark 2.3 and Example 3.1). Theorem 3.1 is a "variation of parameters formula" for the system (1.2). Using Theorem 3.1 and an auxilliary result (Lemma 2.1), we obtain in Theorem 3.2, asymptotic stability 
of the null solution of (1.2), employing the techniques of Brauer [1] and Strauss and Yorke [8]. When the impulses cease to act, that is when $u$ is an absolutely continuous function, our results reduce to the corresponding ones known for ordinary differential equations [2].

2. Preliminaries and basic results. Let $J=\left[t_{0}, \infty\right), t_{0} \geqq 0$ and $R^{n}$ denote the $n$-Euclidean space with any convinient norm $|\cdot|$. The same symbol will be used to denote the norm of an $n$ by $n$ matrix. Consider (1.2) where $x \in R^{n}, A$ is an $n$ by $n$ matrix, $u: J \rightarrow R$ is a right-continuous function of bounded variation on every compact sub-interval of $J, f: J \times R^{n} \rightarrow R^{n}$ is Lebesgue integrable, $g: J \times R^{n} \rightarrow R^{n}$ is integrable with respect to the Lebesgue-Stieltjes measure $d u$ and $D x, D u$ denote the distributional derivatives of $x$ and $u$ respectively.

A function $x(t)=x\left(t, t_{0}, x_{0}\right)$ is a solution of (1.2) on $J$ if and only if it satisfies the integral equation

$$
x(t)=x_{0}+\int_{t_{0}}^{t} f(s, x(s)) d s+\int_{t_{0}}^{t}[A x(s)+g(s, x(s))] d u(s) .
$$

For the proof of this and for the definition of solution of (1.2), along with other relevent details, see [3].

REMARK 2.1. In equation (1.2), $f(t, x)+A x D u+g(t, x) D u$ is identified with the derivative (in the sense of distributions) of

$$
\int_{t_{0}}^{t} f(s, x(s)) d s+\int_{t_{0}}^{t}[A x(s)+g(s, x(s))] d u(s) .
$$

When $u$ is an absolutely continuous function, it has the identification $f(t, x)+[A x+g(t, x)] u^{\prime}$, where $u^{\prime}$ is the ordinary derivative (which exists a.e. on $J$ ) of $u$. In particular, if $u^{\prime} \equiv 1$, (1.2) reduces to the conventional system $x^{\prime}=f(t, x)+A x+g(t, x)$.

Let $t_{1}<t_{2}<\cdots$ denote the discontinuities of $u$ such that $t_{1}>t_{0}$ and $t_{k} \rightarrow \infty$ as $k \rightarrow \infty$. Suppose further that these discontinuities are isolated. Throughout this paper, except in Lemma 2.1 (in which $u$ may be any function of bounded variation), we assume that $u$ has the form

$$
u(t)=t+\sum_{k=1}^{\infty} a_{k} H_{k}(t) ; H_{k}(t)=\left\{\begin{array}{l}
0, \text { for } t<t_{k} \\
1, \text { for } t \geqq t_{k}
\end{array}\right.
$$

where $a_{k}$ are real numbers. Generally, a right-continuous function of bounded variation contains an absolutely continuous part and a singular part. The latter usually resembles $\sum_{k=1}^{\infty} a_{k} H_{k}(t)$ when the 
discontinuities (which are obviously countable) are isolated. The above assumption is thus reasonable. Moreover, in this case, the predominent effect of the impulses can be visualized. It follows from (2.2) that

$$
D u=1+\sum_{k=1}^{\infty} a_{k} \delta\left(t_{k}\right)
$$

where $\delta\left(t_{k}\right)$ is the Dirac measure concentrated at $t_{k}$. Note that $u^{\prime} \equiv 1$ a.e. on $J$. For any $t \in J$, it is clear that there is a unique integer $k \geqq 1$ such that $t \in\left[t_{k-1}, t_{k}\right)$.

Let $B_{k}=E-a_{k} A, k=1,2, \cdots$ where $E$ is the identity $n$ by $n$ matrix. From the assumptions on $u$, it is easy to establish the following.

THEOREM 2.1. Let $B_{k}$ be nonsingular for each $k=1,2 \cdots$. Then, for $t \in\left[t_{k-1}, t_{k}\right.$ ) and any $x_{0} \in R^{n}$, the (unique) solution $x(t)=$ $x\left(t, t_{0}, x_{0}\right)$ of $(1.3)$ is given by

$$
x(t)=\left(\prod_{i=1}^{k-1} B_{k-i}^{-1}\right) e^{\left(t-t_{0}\right) A} x_{0} .
$$

(Here the product $\prod_{i=1}^{k-1}$ is to be understood as $E$ if $k=1$.)

REMARK 2.2. If $a_{k}=0$ for all $k$, then $B_{k}(=E)$ is clearly invertible. In this case, (2.3) reduces to $x(t)=e^{\left(t-t_{0}\right) A} x_{0}$, which obviously solves $x^{\prime}=A x$. On the other hand, if $a_{k} \neq 0$ for some $k$, then a sufficient condition for $B_{k}$ to be invertible is that $a_{k}^{-1}$ is not an eigenvalue of $A$.

REMARK 2.3. Suppose $a_{k}^{-1}$ is an eigenvalue of $A$ for some $k$. Then, in general, the solution $x(t)$ of (1.3) does not exist at $t=t_{k}$. If $x_{0}=0$, then $x(t)$ is arbitrarily determined at $t=t_{k}$.

We need the following lemma which is similar to Lemma 2 in [1] or Lemma 3.6 in [8], when $u$ is an absolutely continuous function.

LEMMA 2.1. Let $u$ be a scalar function of bounded variation on $\left[t_{0}, T\right]$ and let $v$ denote the total variation function of $u$. Suppose that $r$ and $p$ are non-negative, scalar functions such that $r$ is integrable and $p$ is dv-integrable on $\left[t_{0}, T\right]$. Then, for any positive constants $c$ and $M$, the inequality

$$
r(t) \leqq c+\int_{t_{0}}^{t} M r(s) d s+\int_{t_{0}}^{t} p(s) d v(s), \quad t \in\left[t_{0}, T\right]
$$




$$
r(t) \leqq c e^{M\left(t-t_{0}\right)}+\int_{t_{0}}^{t} e^{M(t-s)} p(s) d v(s), \quad t \in\left[t_{0}, T\right]
$$

Proof. Clearly, $r(t) \leqq y(t)$, where $y(t)$ is the maximal solution of the integral equation

$$
y(t)=c+\int_{t_{0}}^{t} M y(s) d s+\int_{t_{0}}^{t} p(s) d v(s), \quad t \in\left[t_{0}, T\right]
$$

Therefore, it is enough to show that any solution of (2.6) satisfies the inequality

$$
y(t)<(c+\delta) e^{M\left(t-t_{0}\right)}+\int_{t_{0}}^{t} e^{M(t-s)} p(s) d v(s)=z(t)
$$

for $t \in\left[t_{0}, T\right]$ and for every $\delta>0$. This will obviously follow if we show that $z(t)$ in (2.7) is a solution of the equation

$$
z(t)=(c+\delta)+\int_{t_{0}}^{t} M z(s) d s+\int_{t_{0}}^{t} p(s) d v(s)
$$

Here, for the right hand side of (2.8), we obtain

$$
\begin{gathered}
(c+\delta)+\int_{t_{0}}^{t} M z(s) d s+\int_{t_{0}}^{t} p(s) d v(s) \\
=(c+\delta)+\int_{t_{0}}^{t} M(c+\delta) e^{M\left(s-t_{0}\right)} d s+\int_{t_{0}}^{t} M e^{M s}\left\{\int_{t_{0}}^{s} e^{-M \tau} p(\tau) d v(\tau)\right\} d s \\
\quad+\int_{t_{0}}^{t} p(s) d v(s) .
\end{gathered}
$$

Denote the first two integrals on the right hand side of (2.9) by $I^{\prime}$ and $I^{\prime \prime}$ respectively. Then

$$
I^{\prime}=(c+\delta) e^{M\left(t-t_{0}\right)}-(c+\delta),
$$

and, integration by parts yields

$$
\begin{aligned}
I^{\prime \prime} & =\int_{t_{0}}^{t}\left\{\int_{t_{0}}^{s} e^{-M \tau} p(\tau) d v(\tau) d\left(e^{M s}\right)\right. \\
& =\int_{t_{0}}^{t} e^{M(t-s)} p(s) d v(s)-\int_{t_{0}}^{t} e^{M s} d\left(\int_{t_{0}}^{s} e^{-M \tau} p(\tau) d v(\tau)\right) \\
& =\int_{t_{0}}^{t} e^{M(t-s)} p(s) d v(s)-\int_{t_{0}}^{t} p(s) d v(s) .
\end{aligned}
$$

From (2.9)-(2.11), it follows that the equation (2.8) reduces to identity, which of course, was our objective. This completes the proof of the lemma.

3. Variation of parameters formula and a stability result. It is well known that an important technique in obtaining the 
qualitative properties of solutions of linear and nonlinear ordinary differential equations under perturbations, is through the use of the variation of parameters formula. The theorem that follows gives an analytic expression for solutions of (1.2) in terms of solution of (1.3) and the strength of the impulses $a_{k}$. In the absence of the impulses, the result reduces to the well known formula for ordinary differential equations [2].

THEOREM 3.1. Let the conditions of Theorem 2.1 hold. Then, for $t \in\left[t_{k-1}, t_{k}\right)$, any solution $y(t)=y\left(t, t_{0}, x_{0}\right)$ of $(1.2)$ is given by

$$
\begin{aligned}
y(t)=x(t) & +\int_{t_{0}}^{t} e^{(t-s) A} f(s, y(s)) d s+\int_{t_{0}}^{t} e^{(t-s) \cdot A} g(s, y(s)) d u(s) \\
& +e^{t A} \sum_{i=1}^{k-1} a_{i}\left(\prod_{j=1}^{k-i} B_{k-j}^{-1}\right) A\left(I_{i}+J_{i}\right)
\end{aligned}
$$

where $x(t)$ is given by (2.3) and

$$
I_{i}=\int_{t_{0}}^{t_{i}} e^{-s A} f(s, y(s)) d s ; J_{i}=\int_{t_{0}}^{t_{i}} e^{-s A} g(s, y(s)) d u(s), 1 \leqq i \leqq k-1 .
$$

Proof. Since $u(t)=t$ for $t \in\left[t_{0}, t_{1}\right)$, we have

$$
\begin{aligned}
y(t)=e^{\left(t-t_{0}\right) A} x_{0} & +\int_{t_{0}}^{t} e^{(t-s) A} f(s, y(s)) d s \\
& +\int_{t_{0}}^{t} e^{(t-s) A} g(s, y(s)) d u(s), t \in\left[t_{0}, t_{1}\right) .
\end{aligned}
$$

At $t=t_{1},(2.1)$ gives

$$
\begin{aligned}
y\left(t_{1}\right)=y\left(t_{1}-h\right) & +\int_{t_{1}-h}^{t_{1}} f(s, y(s)) d s \\
& +\int_{t_{1}-h}^{t_{1}}[A y(s)+g(s, y(s))] d u(s)
\end{aligned}
$$

where $h>0$. Letting $h \rightarrow 0_{+}$and using the fact that

$$
\lim _{h \rightarrow 0_{+}} \int_{t_{1}-h}^{t_{1}} f(s, y(s)) d s=0,
$$

we obtain from (3.2) and (3.3),

$$
\begin{gathered}
y\left(t_{1}\right)=e^{t_{1} 4}\left[e^{-t_{0} \cdot 4} x_{0}+I_{1}+\int_{t_{0}}^{t_{1}-} e^{-s .4} g(s, y(s)) d u(s)\right] \\
+a_{1} A y\left(t_{1}\right)+a_{1} g\left(t_{1}, y\left(t_{1}\right)\right) .
\end{gathered}
$$

Now,

$$
\int_{t_{0}}^{t_{1}-} e^{\left(t_{1}-s\right) A} g(s, y(s)) d u(s)+a_{1} g\left(t_{1}, y\left(t_{1}\right)\right)=e^{t_{1} A} J_{1}
$$


Therefore, in view of the facts that $B_{1}$ is inverticle, and $B_{1}^{-1}$ and $e^{t_{1} A}$ commute with each other, (3.4) yields

$$
\begin{aligned}
y\left(t_{1}\right) & =B_{1}^{-1} e^{t_{1} A}\left[e^{-t_{0} A} x_{0}+I_{1}+J_{1}\right] \\
& =x\left(t_{1}\right)+e^{t_{1} A}\left[I_{1}+J_{1}+a_{1} B_{1}^{-1} A\left(I_{1}+J_{1}\right)\right] .
\end{aligned}
$$

For $t \in\left[t_{1}, t_{2}\right)$, we know that

$$
\begin{aligned}
y(t)=e^{\left(t-t_{1}\right) A} y\left(t_{1}\right) & +\int_{t_{1}}^{t} e^{(t-s) d} f(s, y(s)) d s \\
& +\int_{t_{1}}^{t} e^{(t-s) A} g(s, y(s)) d u(s),
\end{aligned}
$$

where $y\left(t_{1}\right)$ is determined by (3.5). Thus

$$
\begin{aligned}
y(t)=x(t) & +\int_{t_{0}}^{t} e^{(t-s) A} f(s, y(s)) d s+\int_{t_{0}}^{t} e^{(t-s) A} g(s, y(s)) d u(s) \\
& +e^{t A} a_{1} B_{1}^{-1} A\left(I_{1}+J_{1}\right), t \in\left[t_{1}, t_{2}\right) .
\end{aligned}
$$

As above, it can be shown that

$$
y\left(t_{2}\right)=e^{t_{2} A}\left[I_{2}+J_{2}+\sum_{i=1}^{2} a_{i}\left(\prod_{j=1}^{3-i} B_{3-j}^{-1}\right) A\left(I_{i}+J_{i}\right)\right] .
$$

In general, for $t \in\left[t_{k-1}, t_{k}\right)$, (3.1) follows by induction, completing the proof of the theorem.

Assume the following hypothesis:

$\left(\mathrm{H}_{1}\right)$ given any $\varepsilon>0$, there exist $\delta(\varepsilon)>0$ and $T(\varepsilon)>t_{0}$ such that

$$
|f(t, x)| \leqq \varepsilon|x|, \text { for }|x| \leqq \delta(\varepsilon) \text { and } t \geqq T(\varepsilon) ;
$$

$\left(\mathrm{H}_{2}\right) \quad g$ satisfies

$$
|g(t, x)| \leqq p(t), \text { for } t \geqq t_{0} \text { and }|x| \leqq r, r>0
$$

where $p$ is a $d v$-integrable $(v(t)$ is the total variation function of $u(t)$ on $\left.\left[t_{0}, t\right], t \in J\right)$ function such that

$$
\int_{t_{0}}^{\infty} p(s) d v(s)<\infty ;
$$

$\left(\mathrm{H}_{3}\right)$ there exist constants $P$ and $Q$ such that

$$
\left(\prod_{i=1}^{k}\left|B_{i}^{-1}\right|\right) \quad \text { and } \sum_{i=1}^{k}\left|a_{i} A\right|\left(\sum_{j=i}^{k}\left|B_{j}^{-1}\right|\right)
$$

are bounded by $P$ and $Q$ respectively, as $k \rightarrow \infty$.

Note that, for each $c>0$, (3.6) implies

$$
\lim _{t \rightarrow \infty} e^{-c t} \int_{t_{0}}^{t} e^{c s} p(s) d v(s)=0 .
$$


THEOREM 3.2. Let $\left(\mathrm{H}_{1}\right)-\left(\mathrm{H}_{2}\right)$ hold. Suppose that all the characteristic roots of $A$ have negative real parts. Then, under the conditions of Theorem 3.1, there exist $T_{0}$ and $\delta>0$ such that for every $t_{0} \geqq T_{0}$ and $x_{0}$ with $\left|x_{0}\right|<\delta$, any solution $y(t)=y\left(t, t_{0}, x_{0}\right)$ of (1.2) satisfies $|y(t)| \rightarrow 0$ as $t \rightarrow \infty$. In particular, if (1.2) possesses the null solution, then it is asymptotically stable.

Proof. Let $t \in J$ be arbitrary. Then there is an index $k$ such that $t \in\left[t_{k-1}, t_{k}\right)$. Since all the characteristic roots of $A$ have negative real parts, there are positive constants $K$ and $\alpha$ such that $\left|e^{t A}\right| \leqq$ $K e^{-\alpha t}$, for all $t>0$. Let $0<\varepsilon<\min \left(\alpha M^{-1}, r\right)$, where $M=K(Q+1)$. By $\left(\mathrm{H}_{1}\right)$, choose $T(\varepsilon)$ and $\delta(\varepsilon)$ so that $T(\varepsilon)>t_{0}$ and $\delta(\varepsilon) \leqq \varepsilon$. Select $T_{0} \geqq T(\varepsilon)$ so large that (by $(3.7)$ ),

$$
\int_{t_{0}}^{t} e^{-(\alpha-M \varepsilon)(t-s)} p(s) d v(s)<(2 M)^{-1} \delta(\varepsilon), \text { for } t \geqq T_{0} .
$$

Let $\delta=(2 P K)^{-1} \delta(\varepsilon)$, and consider any $t_{0} \geqq T_{0}$ and $x_{0}$ satisfying $\left|x_{0}\right|<\delta$. From (2.3), (3.1) and the conditions of the theorem, we then have

$$
\begin{aligned}
|y(t)| \leqq P K \delta e^{-\alpha\left(t-t_{0}\right)} & +\int_{t_{0}}^{t} M \varepsilon e^{-\alpha(t-s)}|y(s)| d s \\
& +\int_{t_{0}}^{t} M e^{-\alpha(t-s)} p(s) d v(s),
\end{aligned}
$$

as long as $|y(t)|<\delta(\varepsilon)$. By Lemma 2.1, this gives

$$
|y(t)| \leqq P K \delta e^{-\langle\alpha-M \varepsilon)\left(t-t_{0}\right)}+M \int_{t_{0}}^{t} e^{-(\alpha-M \varepsilon)(t-s)} p(s) d v(s),
$$

from which the conclusion of the theorem follows in the usual way (see $[1,8]$ ).

Theorem 3.2 remains valid if the condition (3.6) in $\left(\mathrm{H}_{2}\right)$ is replaced by a more general condition

$$
\int_{t}^{t+1} p(s) d v(s) \longrightarrow 0 \text { as } t \longrightarrow \infty \text {. }
$$

Example 3.1. Let $J=[0, \infty)$. Consider the system (1.3) where

$$
x=\left[\begin{array}{l}
x_{1} \\
x_{2}
\end{array}\right] \text { and } A=\left[\begin{array}{ll}
2 & 5 \\
0 & 2
\end{array}\right] .
$$

Let $t_{k}=k$ and $a_{k}=k^{-1}$ for $k=1,2, \cdots$. Then $a_{2}^{-1}$ is an eigenvalue of $A$ but $a_{1}^{-1}$ is not. Choose $x_{0}=\left[\begin{array}{l}0 \\ 1\end{array}\right]$. It can be verified that the solution of (1.3) through $\left(0, x_{0}\right)$ on the interval $[0,2)$ is given by 


$$
x_{1}(t)=\left\{\begin{array}{ll}
5 t e^{2 t}, & 0 \leqq t<1 \\
5(1-t) e^{2 t}, & 1 \leqq t<2
\end{array}, \quad x_{2}(t)=\left\{\begin{array}{ll}
e^{2 t}, & 0 \leqq t<1 \\
-e^{2 t}, & 1 \leqq t<2
\end{array} .\right.\right.
$$

However, $x(t)$ does not exist at $t=2$. If we choose $x_{0}=\left[\begin{array}{l}0 \\ 0\end{array}\right]$, then $x(t)=\left[\begin{array}{l}0 \\ 0\end{array}\right]$ for $0 \leqq t<2$, whereas $x(2)=\left[\begin{array}{l}c \\ 0\end{array}\right], c$ an arbitrary constant.

EXAMPLE 3.2. Let $J=[1, \infty)$. Choose $A=-1, t_{k}=k$ and $a_{k}=$ $2\left(k^{3}-1\right)^{-1}$ for $k=2,3, \cdots$. Then the hypothesis $\left(\mathrm{H}_{3}\right)$ is satisfied. Indeed, we have

$$
\prod_{k=2}^{\infty}\left|B_{k}^{-1}\right|=\prod_{k=2}^{\infty}\left(1-2\left(k^{3}+1\right)^{-1}\right)=2 / 3
$$

and

$$
\lim _{k \rightarrow \infty} \sum_{i=2}^{k}\left|a_{i} A\right|\left(\prod_{j=1}^{k}\left|B_{j}^{-1}\right|\right) \sum_{k=2}^{\infty} 2 k^{-2}<\infty
$$

ACKNOWLEDGMENT. The author gratefully acknowledges valuable discussions with Dr. V. Raghavendra while this paper was prepared.

\section{REFERENCES}

1. F. Brauer. Nonlinear differential equations with forcing terms, Proc. Amer. Math. Soc., 15 (1964), 758-765.

2. E. A. Coddington and N. L. Levinson, Theory of Ordinary Differential Equations, Tata McGraw-Hill, Bombay-New Delhi.

3. P. C. Das and R. R. Sharma, Existence and stability of measure differential equations, Czech. Math. J., 22 (97), (1972), 145-158.

4. S. Leela, Stability of measure differential equations, Pacific J. Math., 55 (1974), 489-498.

5. - Stability of differential systems with impulsive perturbations in terms of two measures, Nonlinear Analysis: Theory, Methods and Applications, 1(6), (1977), 667-677.

6. V. Raghavendra and M. Rama Mohana Rao, Stability of impulsively perturbed differential equations and extension of Lyapunov's method, to appear.

7. W. W. Schmaedeke, Optimal control theory for nonlinear vector differential equations containing measures, J. Siam Control, 3 (1965), 231-280.

8. A. Strauss and J. A. Yorke, Perturbation theorems for ordinary differential equations, J. Differential Equations, 3 (1967), 15-30.

Received December 13, 1978.

UNIVERSITY OF BOMBAY

PaNAJI-GoA, 403001, India 


\title{
PACIFIC JOURNAL OF MATHEMATICS
}

\section{EDITORS}

\author{
DoNALD BABBITT (Managing Editor) \\ University of California \\ Los Angeles, CA 90024 \\ HUGo RossI \\ University of Utah \\ Salt Lake City, UT 84112 \\ C. C. MOORE and ANDREW OGG \\ University of California \\ Berkeley, CA 94720
}

J. DugundJI

Department of Mathematics

University of Southern California

Los Angeles, CA 90007

R. FINN and J. Milgram

Stanford University

Stanford, CA 94305

\section{ASSOCIATE EDITORS}
E. F. BeCKenbach
B. H. NeumanN
F. WOLF
K. YoshidA

\section{SUPPORTING INSTITUTIONS}

\author{
UNIVERSITY OF BRITISH COLUMBIA \\ CALIFORNIA INSTITUTE OF TECHNOLOGY \\ UNIVERSITY OF CALIFORNIA \\ MONTANA STATE UNIVERSITY \\ UNIVERSITY OF NEVADA, RENO \\ NEW MEXICO STATE UNIVERSITY \\ OREGON STATE UNIVERSITY \\ UNIVERSITY OF OREGON
}

\author{
UNIVERSITY OF SOUTHERN CALIFORNIA \\ STANFORD UNIVERSITY \\ UNIVERSITY OF HAWAII \\ UNIVERSITY OF TOKYO \\ UNIVERSITY OF UTAH \\ WASHINGTON STATE UNIVERSITY \\ UNIVERSITY OF WASHINGTON
}

The Supporting Institutions listed above contribute to the cost of publication of this Journal, but they are not owners or publishers and have no responsibility for its content or policies.

Mathematical papers intended for publication in the Pacific Journal of Mathematics should be in typed form or offset-reproduced, (not dittoed), double spaced with large margins. Please do not use built up fractions in the text of the manuscript. However, you may use them in the displayed equations. Underline Greek letters in red, German in green, and script in blue. The first paragraph or two must be capable of being used separately as a synopsis of the entire paper. Please propose a heading for the odd numbered pages of less than 35 characters. Manuscripts, in triplicate, may be sent to any one of the editors. Please classify according to the scheme of Math. Reviews, Index to Vol. 39. Supply name and address of author to whom proofs should be sent. All other communications should be addressed to the managing editor, or Elaine Barth, University of California, Los Angeles, California, 90024.

50 reprints to each author are provided free for each article, only if page charges have been substantially paid. Additional copies may be obtained at cost in multiples of 50 .

The Pacific Journal of Mathematics is issued monthly as of January 1966. Regular subscription rate: $\$ 84.00$ a year $(6$ Vols., 12 issues). Special rato: $\$ 42.00$ a year to individual members of supporting institutions.

Subscriptions, orders for numbers issued in the last three calendar years, and changes of address shoud be sent to Pacific Journal of Mathematics, P.O. Box 969, Carmel Valley, CA 93924, U.S.A Old back numbers obtainable from Kraus Periodicals Co., Route 100, Millwood, NY 10546.

\section{PUBLISHED BY PACIFIC JOURNAL OF MATHEMATICS, A NON-PROFIT CORPORATION}

Printed at Kokusai Bunken Insatsusha (International Academic Printing Co., Ltd.). 8-8, 3-chome, Takadanobaba, Shinjuku-ku, Tokyo 160, Japan. 


\section{Pacific Journal of Mathematics}

\section{Vol. 86, No. 2 December, 1980}

Graham Donald Allen, David Alan Legg and Joseph Dinneen Ward, Hermitian

liftings in Orlicz sequence spaces ............................... 379

George Bachman and Alan Sultan, On regular extensions of measures ........ 389

Bruce Alan Barnes, Representations Naimark-related to $*$-representations; a

correction: "When is a representation of a Banach $*$-algebra

Naimark-related to a $*$-representation?" ........................ 397

Earl Robert Berkson, One-parameter semigroups of isometries into $H^{p} \ldots \ldots .403$

M. Brodmann, Piecewise catenarian and going between rings ............ 415

Joe Peter Buhler, A note on tamely ramified polynomials ............... 421

William Lee Bynum, Normal structure coefficients for Banach spaces ........ 427

Lung O. Chung, Biharmonic and polyharmonic principal functions ......... 437

Vladimir Drobot and S. McDonald, Approximation properties of polynomials

with bounded integer coefficients .............................

Giora Dula and Elyahu Katz, Recursion formulas for the homology of

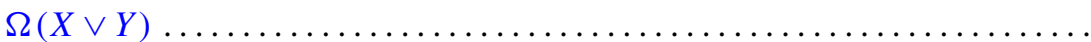

John A. Ernest, The computation of the generalized spectrum of certain Toeplitz operators ...................................... 463

Kenneth R. Goodearl and Thomas Benny Rushing, Direct limit groups and the

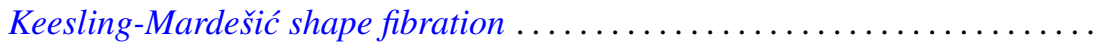

Raymond Heitmann and Stephen Joseph McAdam, Good chains with bad contractions

Patricia Jones and Steve Chong Hong Ligh, Finite hereditary near-ring-semigroups .

Yoshikazu Katayama, Isomorphisms of the Fourier algebras in crossed

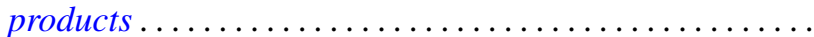

Meir Katchalski and Andrew Chiang-Fung Liu, Symmetric twins and common transversals. .

Mohammad Ahmad Khan, Chain conditions on subgroups of LCA groups ....

Helmut Kröger, Padé approximants on Banach space operator equations ...

Gabriel Michael Miller Obi, An algebraic extension of the Lax-Milgram theorem . .

S. G. Pandit, Differential systems with impulsive perturbation .

Richard Pell, Support point functions and the Loewner variation ...

J. Hyam Rubinstein, Dehn's lemma and handle decompositions of some

4-manifolds

James Eugene Shirey, On the theorem of Helley concerning finite-dimensional subspaces of a dual space.

Oved Shisha, Tchebycheff systems and best partial bases.... 